Supporting Information

\title{
Raman Scattering Methods for Monitoring the Electric Properties of the Postannealed Bulk Heterojunction
}

\author{
Daxin Zhang ${ }^{1,2,3}$, Shuo Yang ${ }^{4}$, Wenshi Zhao ${ }^{1,2,3}$, Lili Yang ${ }^{3}$, Yang Liu $^{3}$, Maobin Wei ${ }^{3}$, \\ Lei Chen*3 and Jinghai Yang*3 \\ ${ }^{1}$ Changchun Institute of Optics, Fine Mechanics and Physics, Chinese Academy of \\ Sciences, Changchun 130033, P.R. China \\ ${ }^{2}$ University of Chinese Academy of Sciences, Beijing 100049, P.R. China \\ ${ }^{3}$ Key Laboratory of Functional Materials Physics and Chemistry of the Ministry of \\ Education, Jilin Normal University, Changchun 130103, P.R. China \\ ${ }^{4}$ College of Science, Changchun University, Changchun 130022, P.R. China
}

*To whom correspondence should be addressed.

E-mail: chenlei@jlnu.edu.cn; jhyang1@jlnu.edu.cn 


\section{Supplementary Note 1: Experimental section}

\subsection{Chemicals and materials}

Silicon (Si) wafer (100) was purchased from Hefei Kejing Material Technology Co., Ltd. $\mathrm{ZnO}$ with $99.99 \%$ purity were purchased from Beijing Tianrui Science and Technology Development Center. P3HT $\left(\mathrm{M}_{\mathrm{w}}=50,000 \mathrm{~g} / \mathrm{mol}\right)$ and PCBM were Shanghai Aladdin Biochemical Technology Co., LTD. $\mathrm{H}_{2} \mathrm{O}_{2}(30 \%)$ and $\mathrm{NH}_{4} \mathrm{OH}(25 \%)$ were all purchased from National Pharmaceutical Chemical Reagent Co., Ltd. They were the highest purity available and the chemical reagents use without further purified. Deionized ultrapure water $\left(18.25 \mathrm{M} \Omega \mathrm{cm}^{-1}\right)$ and silicon $(\mathrm{Si})$ wafers were used throughout the present study.

\subsection{Characterization}

Morphology andmicrostructure images of the samples were obtained using a JEOL 6500F scanning electron microscope (SEM) and a JEM-2100HR transmission electron microscopy (TEM) respectively, operating at an accelerating voltage of 200 $\mathrm{kV}$. Ultraviolet-visible (UV-Vis) absorption spectra were obtained using a Shimadzu UV-3600 spectrometer.The X-ray diffraction (XRD) measurements was performed on Japan Rigaku D/max-ga X-ray diffractometer with $\mathrm{Cu} K \alpha$ radiation $(\lambda=1.5418 \AA)$ at room temperature. The step size $(2 \theta)$ is $0.01^{\circ}$. Hall measurements were performed with van der Pauw configuration by Lake Shore 7704A at room temperature. All Raman spectra were obtained using a confocal Renishaw Raman system 2000 model microscope spectrometer with a $514 \mathrm{~nm}$ excitation. An optical power of $10 \mathrm{~mW}$ and an acquisition time of $60 \mathrm{~s}$ were used for the excitation conditions.

\subsection{Preparation of the Silicon $(\mathrm{Si})$ wafers}

Silicon (Si) wafers with size of $1 \times 1 \mathrm{~cm}^{2}$ were treated in the a mixed of $\mathrm{H}_{2} \mathrm{O}$ (deionized): $\mathrm{H}_{2} \mathrm{O}_{2}: \mathrm{NH}_{4} \mathrm{OH}=6: 2: 1$, then were washed by ultrasonic using deionized water and alcohol alternately.

\subsection{Preparation of the $\mathrm{ZnO}$ substrates}

The $\mathrm{ZnO}$ substrates were fabricated by a magnetron sputtering system (ATC 1800-F, USA AJA) at the sputtering power of $100 \mathrm{~W}$ for $2 \mathrm{~min}$ as shown in the Figure S1(a). The thickness is $\sim 10 \mathrm{~nm}$ measured by Profile-system. 


\subsection{Preparation of the thin films}

P3HT and PCBM with $5 \mathrm{mg}$ each were dissolved in $2 \mathrm{ml}$ chlorobenzene solvent, and the precursor solution was obtained by oscillation for $1 \mathrm{~h}$. Then, it was spin-coated at $300 \mathrm{rpm} / \mathrm{s}$ for $180 \mathrm{~s}$ and annealed at different temperature for $5 \mathrm{~min}$ in the fume hood as shown in the Figure S1(b) and S1(c). Finally, the junction grows on the surface of the $\mathrm{Si} / \mathrm{ZnO}$ wafers and Figure $\mathrm{S} 1$ is the flow diagram of preparing $\mathrm{BHJ}$ grown on $\mathrm{ZnO}$ surface.

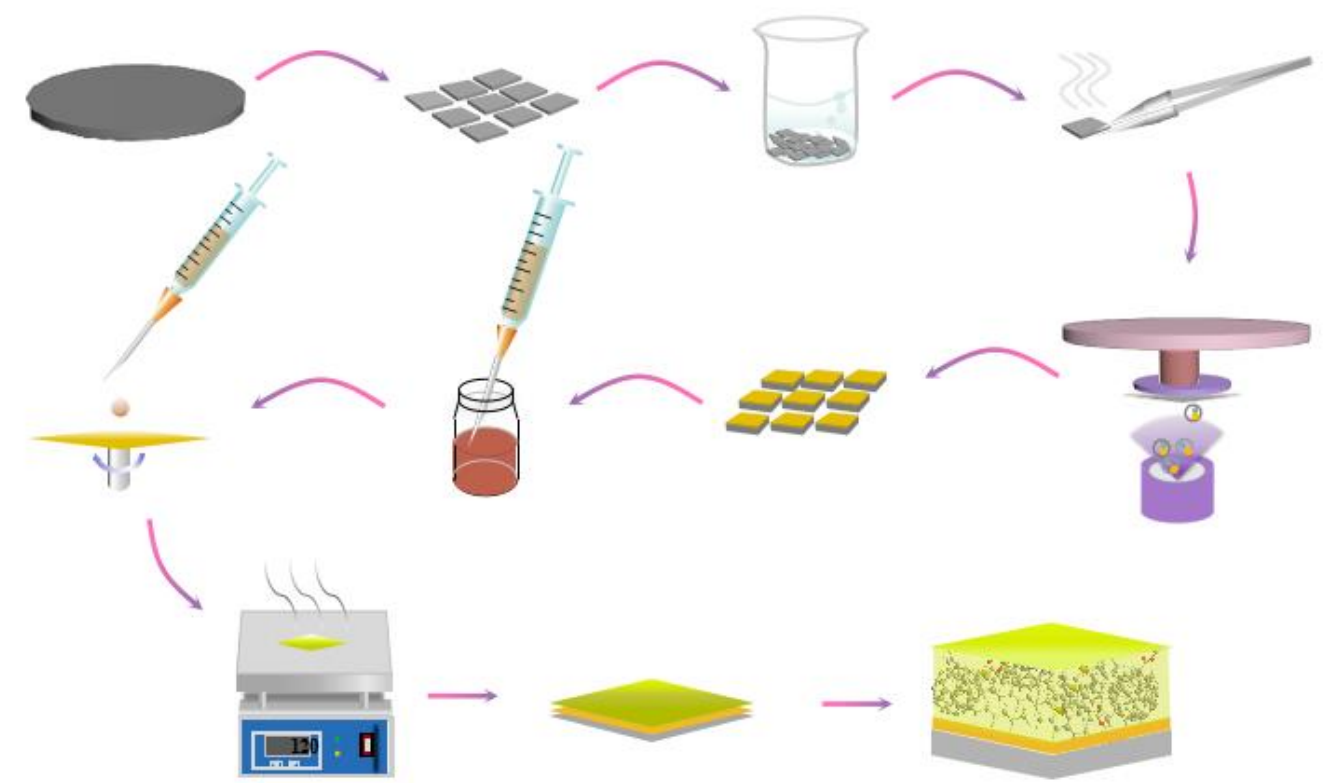

Figure S1. Schematic diagram of the process of preparing the $\mathrm{ZnO} / \mathrm{P} 3 \mathrm{HT}$ :PCBM BHJ thin films. (The film is magnified in different proportions for better presentation.)

\section{Supplementary Note 2: Substrates characterization}

The formation of film plays a decisive role in the performance of the device, and heat treatment is one of the primary means to adjust crystallinity. ${ }^{1}$ The SEM of the P3HT, the PCBM, the P3HT:PCBM (weight to weight=1) at annealing temperature of $100{ }^{\circ} \mathrm{C}$ for 5 min were shown in the Figure S2, respectively. Those thin films are smooth at spin-coated showing the surface have no distinct holes at the field of view . In order to investigate the effect of annealing temperature on the surface morphology of the thin film, SEM images were carried out in Figure S3. Figure S3(a)-(g) were SEM images of P3HT:PCBM (weight to weight=1) thin films annealed from 40 to $200{ }^{\circ} \mathrm{C}$ for $5 \mathrm{~min}$. When the annealing temperature is low, there are holes on the 
surface of the films and the films are not uniform and discontinuous. By increasing of the annealing temperature, the hole area and number decrease. Films spin-coated with annealing temperature above $100{ }^{\circ} \mathrm{C}$ demonstrate a quite homogeneous morphology over the whole region within the field of view.

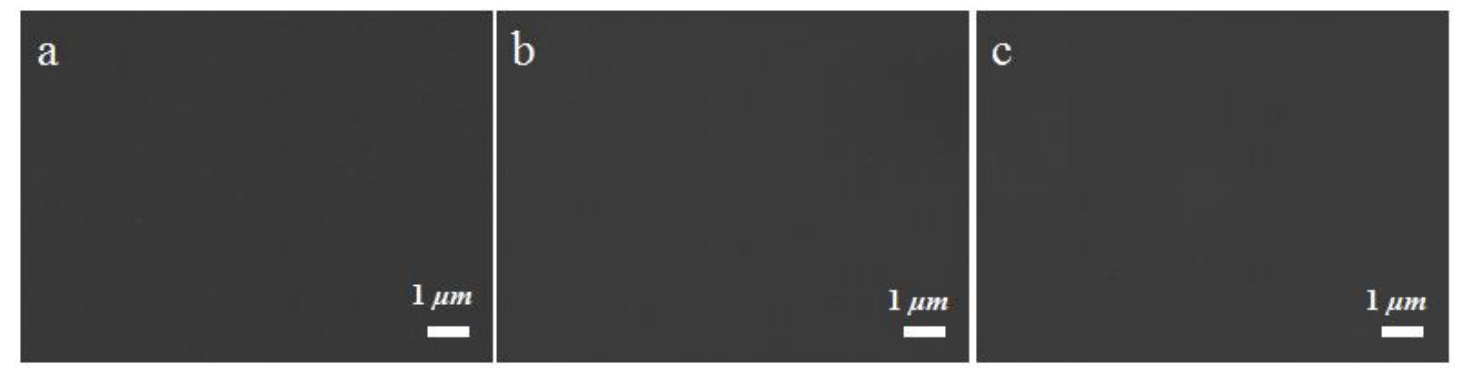

Figure S2. The scanning electron microscopy (SEM) of the P3HT, the PCBM, the P3HT:PCBM (weight to weight $=1$ ) at annealing temperature of $100{ }^{\circ} \mathrm{C}$ for $5 \mathrm{~min}$, respectively.

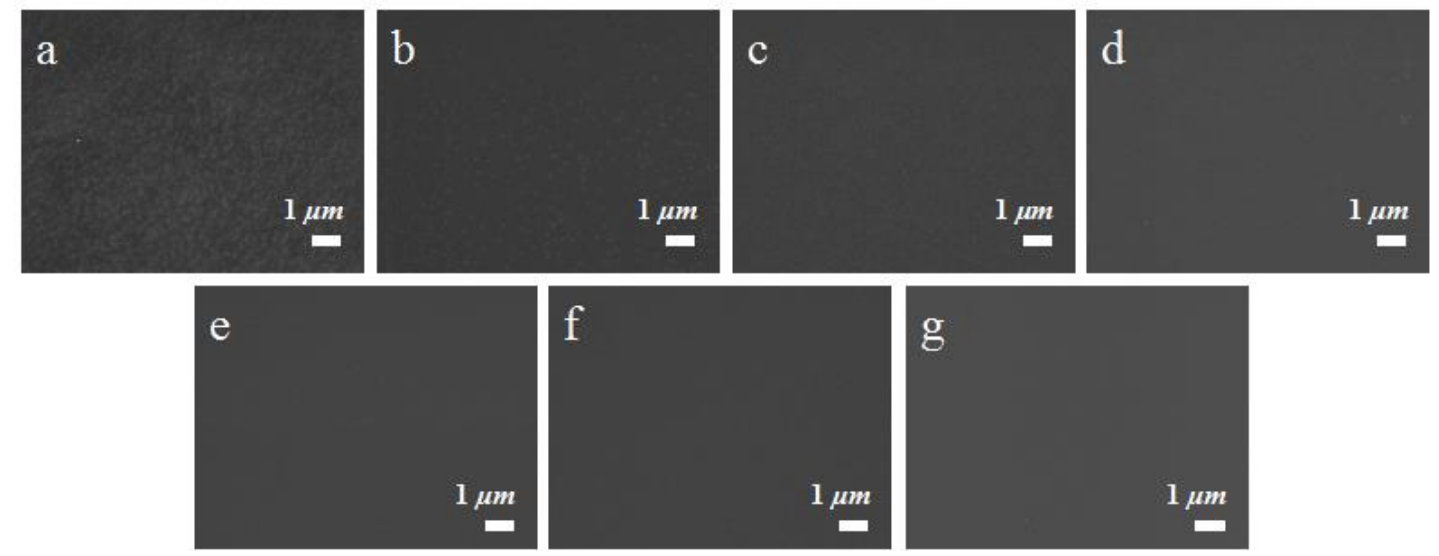

Figure S3. The scanning electron microscopy (SEM) of the P3HT:PCBM (weight to weight $=1$ ) at annealing temperature of $40^{\circ} \mathrm{C}(\mathrm{a}), 60^{\circ} \mathrm{C}(\mathrm{b}), 80^{\circ} \mathrm{C}(\mathrm{c}), 100{ }^{\circ} \mathrm{C}(\mathrm{d}), 120^{\circ} \mathrm{C}$ (e), $140{ }^{\circ} \mathrm{C}(\mathrm{f})$ and $200^{\circ} \mathrm{C}(\mathrm{g})$, respectively.

The structural properties of pure P3HT (powder), pure PCBM (powder) and thin film of P3HT:PCBM (weight to weight $=1$ ) on the Si wafers were studied by XRD. As shown in Figure S4, diffraction angle $2 \theta=5.3^{\circ}, 10.7^{\circ}$ and $15.9^{\circ}$ of the P3HT are corresponding to the primary (100), secondary (200) and tertiary (300) peaks assigned to a-axis orientation (main chain parallel and side chains perpendicular to the substrate) ${ }^{2-4}$ In addition, $2 \theta=24^{\circ}$ respectively originates from the (010) due to the lamella layer structure and the (001) due to $\pi-\pi^{*}$ interchain stacking, indicating that all pristine P3HT films show a well-organized intraplane structure with lamellae 
oriented normal to the substrate. Pure PCBM powder (purple line) shows a distinct diffraction pattern with characteristic narrow peaks studied by XRD. ${ }^{3}$ The crystal preparation was carried out so that only a limited number of crystals, of approximately $500 \mathrm{~nm}$ size, could contribute to the diffraction signals. ${ }^{5}$ However, these peaks are absent in the diffractogram of annealed P3HT:PCBM thin films. ${ }^{6,7}$ Consequently, P3HT:PCBM films (red line) have not the crystalline of the PCBM and only supports the formation of the crystalline P3HT. There is a dominating diffraction peak at $2 \theta=5.3^{\circ}$ of the P3HT, the height of which is proportional to the number of P3HT nanodomains per unit volume. consequently, diffraction peak to the crystallinity of the thin film. The height of the diffraction peak drops diffraction peak at $2 \theta=5.3^{\circ}$ confirmed the crystallinity of P3HT is reduced by the presence of PCBM molecules. Furthermore, a morphology evolution of P3HT:PCBM films was proved that consists of an initial crystallization of P3HT chains, followed by diffusion of PCBM molecules to nucleation sites, at which aggregates of PCBM then grow. ${ }^{8,9}$ In crystalline polymers, such as the archetype poly(3-hexylthiophene) (P3HT) system, addition of PCBM breaks up $\pi$-stacked lamellar chains in aggregates leading to increases in a solution-like amorphous component with higher energy and featureless absorption lineshapes. ${ }^{9-11}$

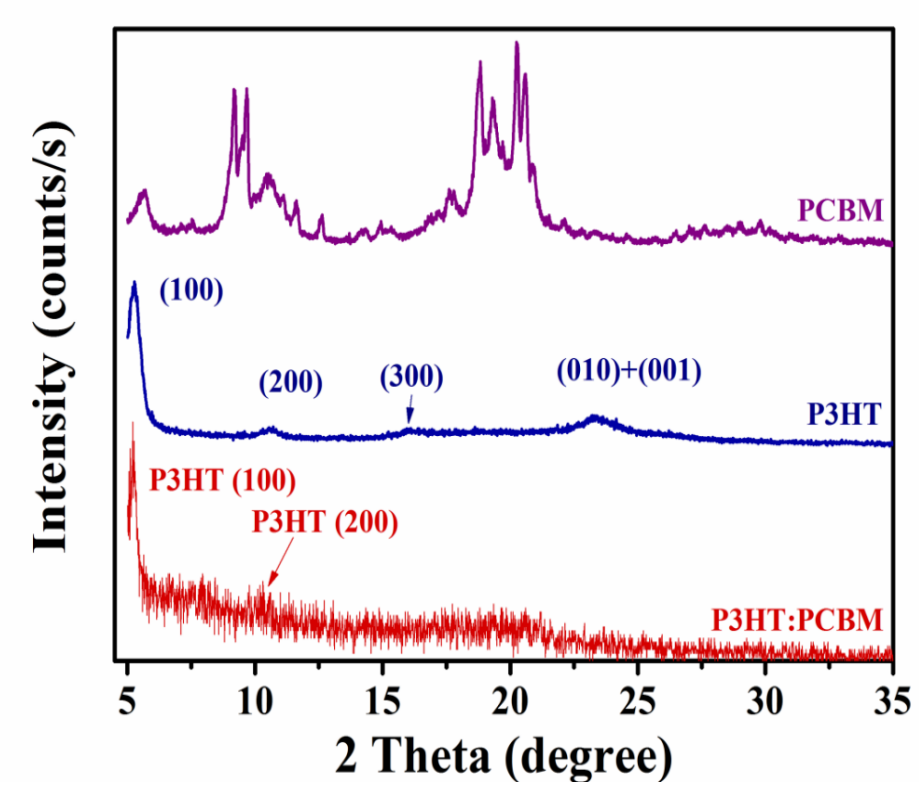

Figure S4. X-ray diffractogram (XRD) of pure P3HT (powder), pure PCBM (powder) 
and thin film of P3HT:PCBM (weight to weight =1) represented on the same scale. Curves are offset for clarity.

\section{Supplementary Note 3: Calculation of $\boldsymbol{E}_{\mathrm{g}}$}

In addition, the energy level difference $(E g)$ is also calculated using the optical coefficient absorption formula, as follows, 7,12

$$
\alpha=(\mathrm{A} / \mathrm{h} v)\left(\mathrm{h} v-E_{g}\right)^{12}
$$

Here, $A$ is proportional constant, and $h v$ is the photon energy. Organic semiconductors are thought of as direct bandgap semiconductors, so diagram of $\alpha h v$ and $h v$ is obtain in Figure S5. The $E g$ of $\mathrm{ZnO}$ is $3.87 \mathrm{eV}$, and the BHJ of the P3HT:PCBM (weight to weight $=1$, without annealing) is $1.88 \mathrm{eV}$. The calculated $E g$ of the blend film at different annealing temperatures remained basically unchanged at $1.9 \mathrm{eV}$. For $E g$, according to the conservation of momentum and energy of excition transitions, is expressed as,

$$
\left\{h \omega=E_{g}+E=E_{g}+\frac{h^{2} k^{2}}{2\left(m_{c}+m_{h}\right)}-\frac{\left(q^{2} 4 \pi \varepsilon \varepsilon_{0}\right)^{2}}{2\left(h^{2} \mu\right) h^{2}}\right.
$$

Here, $\vec{q}=\vec{k} \approx 0$. Then,

$$
h \omega=E_{g}-\frac{\left(q^{2} 4 \pi \varepsilon \varepsilon_{0}\right)^{2}}{2\left(h^{2} \mu\right) h^{2}}
$$

In the UV-Vis absorption spectra (Figure $1(\mathrm{c})$ ), $\Delta \lambda \leq 10, \Delta \omega \approx 0$. The first line of the split energy level is obtained, also known as the lowest energy level difference $E g$, which is expressed as,

$$
E_{g}=\frac{\left(q^{2} 4 \pi \varepsilon \varepsilon_{0}\right)^{2}}{2\left(h^{2} \mu\right) h^{2}}
$$

Here, $\mu *$ is the reduced mass, $\hbar, h, \varepsilon 0$ and $q$ are constant. $E g$ is basically unchanged under the effects of $\varepsilon$ and $\mu^{*}$. In conclusion, the effect of temperature on the energy level difference of the system is negligible, and the effect of temperature on crystal structure is worth further study. 

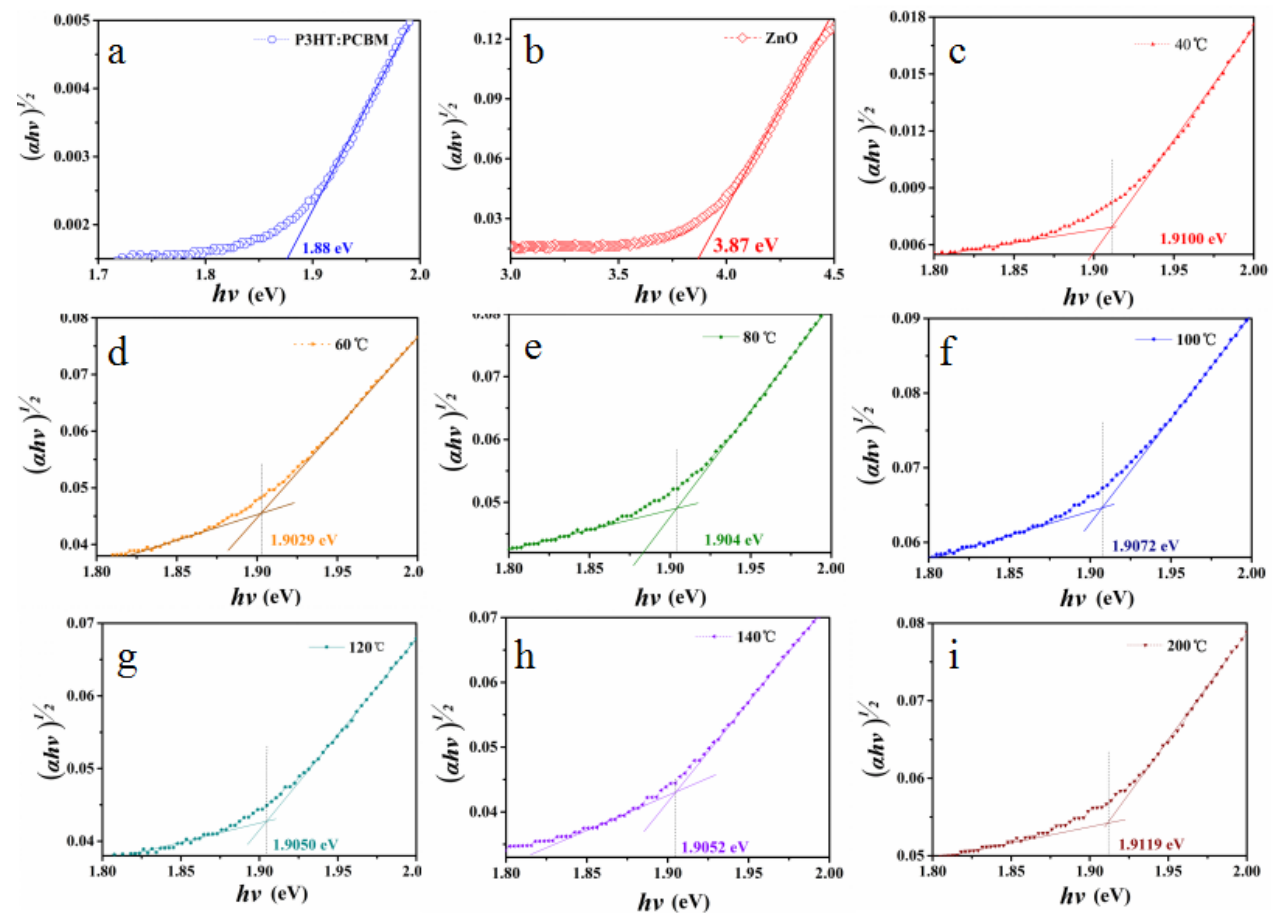

Figure S5. The curve of $(\alpha h v)^{1 / 2}$ and $h v$ of the $\mathrm{ZnO}$ and P3HT:PCBM films (with no annealing and different annealing temperatures).

\section{Supplementary Note 4: The Raman intensity (I) and shift (v) of the BHJ}

Table S1. Normalized Raman intensity $(I)$ and shift $(v)$ of the P3HT:PCBM (weight to weight $=1$ ) at different annealing temperature $(T)$, which are $40{ }^{\circ} \mathrm{C}, 60^{\circ} \mathrm{C}, 80^{\circ} \mathrm{C}, 100{ }^{\circ} \mathrm{C}$ $120^{\circ} \mathrm{C}, 140{ }^{\circ} \mathrm{C}$ and $200^{\circ} \mathrm{C}$, respectively.

\begin{tabular}{cccccccc}
\hline $\boldsymbol{T}\left({ }^{\circ} \mathrm{C}\right)$ & $\mathbf{4 0}$ & $\mathbf{6 0}$ & $\mathbf{8 0}$ & $\mathbf{1 0 0}$ & $\mathbf{1 2 0}$ & $\mathbf{1 4 0}$ & $\mathbf{2 0 0}$ \\
\hline $\boldsymbol{v}\left(\mathbf{c m}^{-1}\right)$ & 1447.9 & 1452.5 & 1455.0 & 1457.0 & 1454.5 & 1451.2 & 1447.7 \\
$\boldsymbol{I}$ (a.u.) & 8609 & 15168 & 28504 & 78766 & 55914 & 29835 & 2260 \\
\hline
\end{tabular}

\section{Supplementary Note 5: The differential thermal analysis diagram}

According to the differential thermal analysis in the Figure S7, it was found that $100{ }^{\circ} \mathrm{C}$ was not the vitrification temperature of $\mathrm{P} 3 \mathrm{HT}$ and $\mathrm{PCBM}$, and the Raman migration caused by sample vitrification was excluded. 

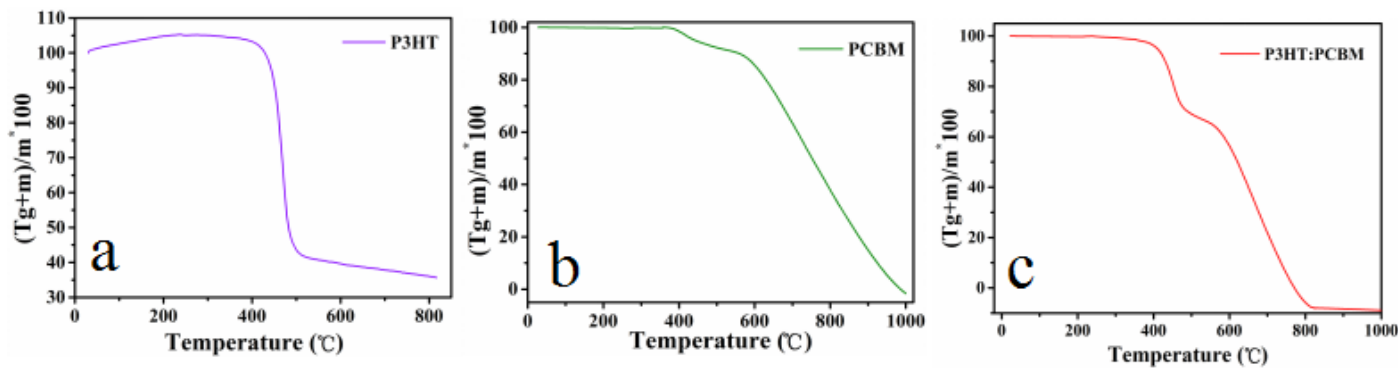

Figure S6. The differential thermal analysis diagram of the samples, which are the P3HT (power), the PCBM (power) and the P3HT:PCBM (power). Here, the samples are $5 \mathrm{mg}$.

Supplementary Note 6: Analysis of the relation of Hall element and annealing temperature

In the Figure 2(d), at low annealing temperature, $I=77462.6-2797.5 \times T+27.93 \times T 2$, and $R^{\prime}(2) 2=0.97863$; at high annealing temperature, $I=-52452.9+5.06 \times T-1$, and $R^{\prime \prime}(2) 2=0.97463$. Combined with the fitting curve (Figure 2), the experimental expression has a turning point of $100{ }^{\circ} \mathrm{C}$. In the Figure S7, when $40^{\circ} \mathrm{C} \leq T \leq 100{ }^{\circ} \mathrm{C}$, $\rho=0.8495+4.999 \mathrm{e}-0.0388 \times T$; when $100{ }^{\circ} \mathrm{C} \leq T \leq 200{ }^{\circ} \mathrm{C}, \rho=0.097+0.0077 \times T$. The regularity of the fitting curve is $99 \%$, indicating a high correlation. Combined with the fitting curve, $n \approx 12.8-0.70 T+0.01 T 2$, and $R 2 \geq 0.99$. When $100{ }^{\circ} \mathrm{C} \leq T \leq 200{ }^{\circ} \mathrm{C}$, $n \approx 4.90 \times 10^{15} \times T^{-7}$, and $R^{2} \geq 0.99$.

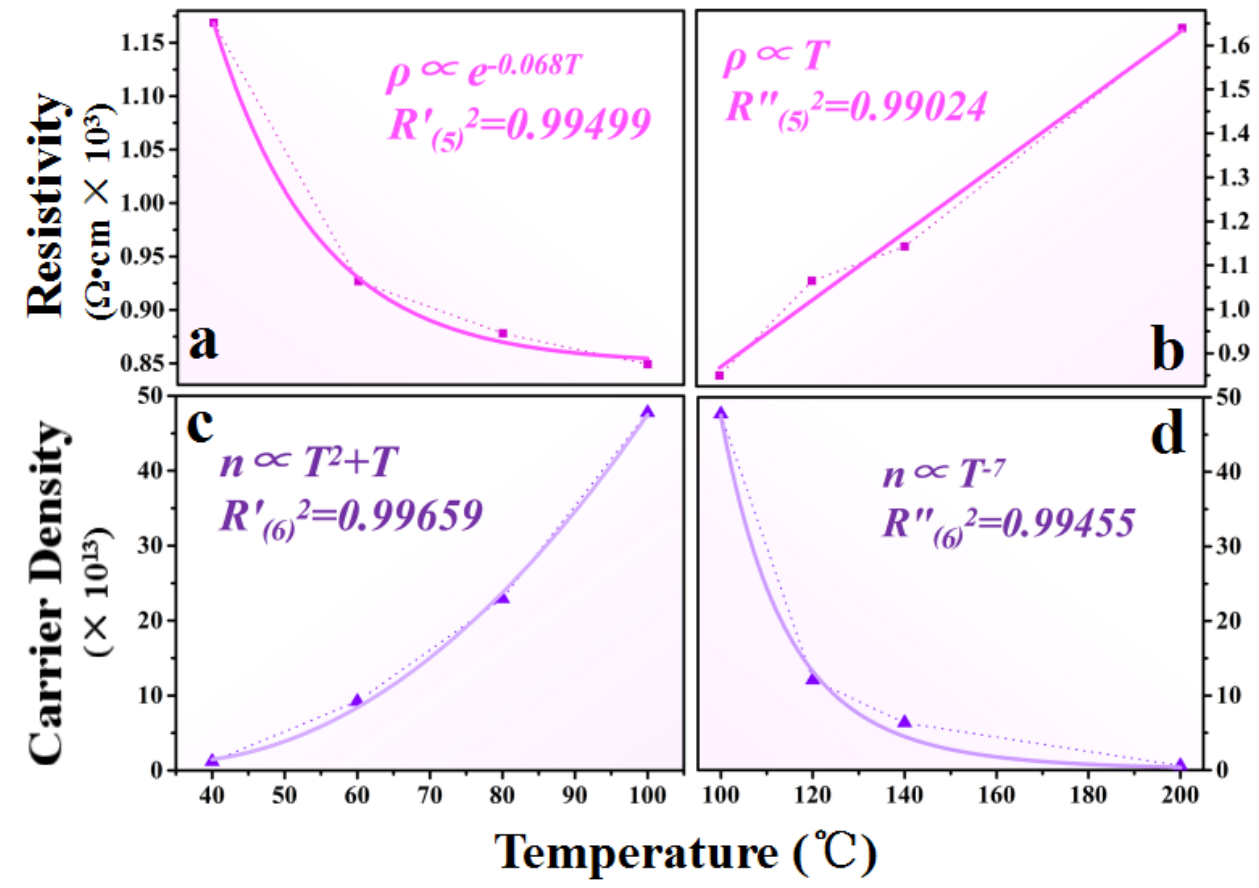


Figure S7. (a, b) The fitting curves of resistivity $(\rho)$ and annealing temperature (T). (c, d) The fitting curves of carrier density $(n)$ and annealing temperature $(T)$.

\section{Supplementary Note 7: Normalized Raman Spectra of the thin film of P3HT and PCBM}

Normalized Raman Spectra of the P3HT and PCBM at different temperatures were respectively shown in Figure S9 and S10. In Figure S9, the Raman signal peak of P3HT basically remains unchanged, which is still at $~ 678,728 \mathrm{~cm}-1$, etc., proving that the structure of P3HT is stable between 40 and $200{ }^{\circ} \mathrm{C}$. what's more, the position at $\sim 678 \mathrm{~cm}-1$ assigned to the band of the symmetric $\mathrm{C} \alpha-\mathrm{S}-\mathrm{C} \alpha$ is also observed in good crystalline state. The intensity of the Raman signal varies little compared to the BHJ and accounts for the main contribution in the heterogeneous junction. It's worth noting that the Raman signal peak located at $\sim 1450 \mathrm{~cm}-1$ has no significant displacement, proved that the displacements in the BHJ do not arise from interaction with P3HT alone. Compared with P3HT, the change of Raman signal in PCBM is intricate in the Figure S10. There are three obviously higher energy Raman signal peaks at $\sim 616,711$ and $1400 \mathrm{~cm}-1$, which are no stretching due to temperature. Nevertheless, The $\operatorname{Ag}(2)$ modes at $1460 \mathrm{~cm}-1$ is stretched, whose Raman shifts are about $5 \mathrm{~cm}-1$. Arguably, the shift of the BHJ is mainly dominated by the chemical bond stretching of $\mathrm{Ag}(2)$ modes of PCBM, but its frequency variable is $10 \mathrm{~cm}-1$ larger than that of PCBM alone, which meant that Raman migration caused by charge transfer between the donor and the receptor occurs at the BHJ (as shown in Figure 4).
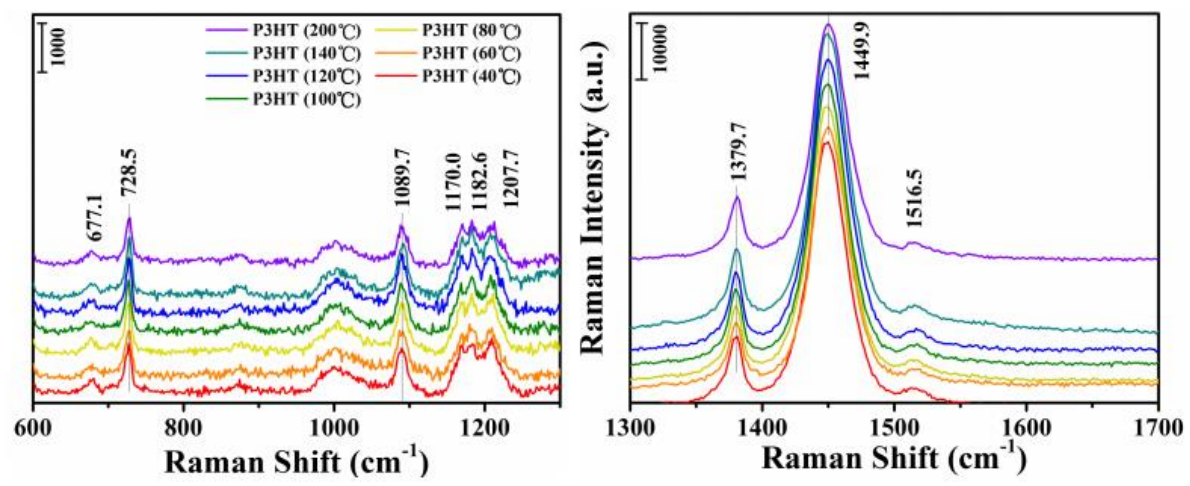

Figure S8. Normalized Raman Spectra of the thin film of P3HT $(2.5 \mathrm{mg} / \mathrm{ml})$ at 
different annealing temperature, which are $40{ }^{\circ} \mathrm{C}, 60^{\circ} \mathrm{C}, 80^{\circ} \mathrm{C}, 100{ }^{\circ} \mathrm{C}, 120^{\circ} \mathrm{C}, 140{ }^{\circ} \mathrm{C}$ and $200{ }^{\circ} \mathrm{C}$, respectively.
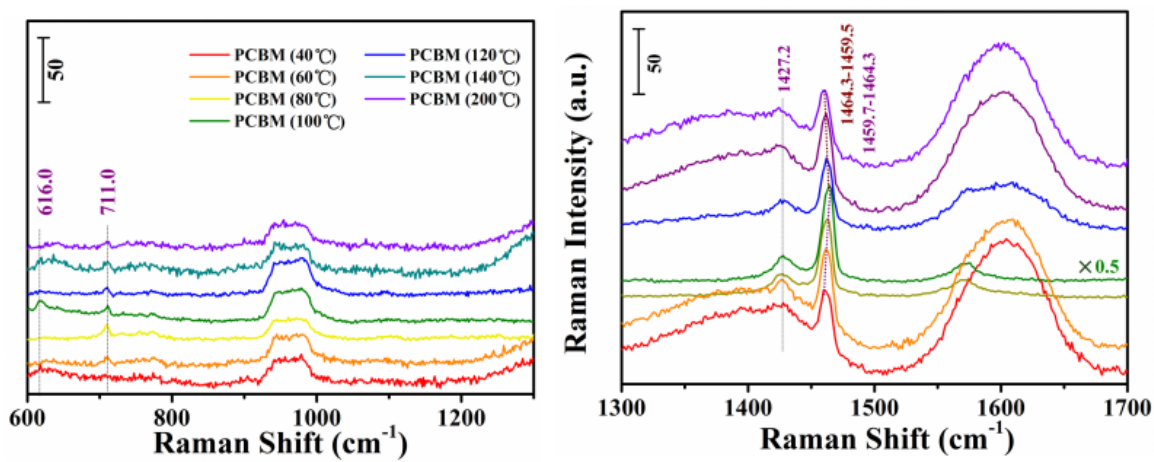

Figure S9. Normalized Raman Spectra of the thin film of PCBM $(2.5 \mathrm{mg} / \mathrm{ml})$ at different annealing temperature, which are $40^{\circ} \mathrm{C}, 60^{\circ} \mathrm{C}, 80^{\circ} \mathrm{C}, 100{ }^{\circ} \mathrm{C}, 120^{\circ} \mathrm{C}, 140{ }^{\circ} \mathrm{C}$ and $200{ }^{\circ} \mathrm{C}$, respectively. 


\section{References:}

1 Tsoi, W. C.; James, D. T.; Kim, J. S.; Nicholson, P. G.; Murphy, C. E.; Bradley, D. D. C.; Nelson, J.; Kim, J. S. The nature of in-plane skeleton Raman modes of P3HT and their correlation to the degree of molecular order in P3HT:PCBM blend thin films. J. Am. Chem. Soc. 2011, 133(25), 9834-43.

2 Kim, Y.; Cook, S.; Tuladhar, S. M.; Choulis, S. A.; Nelson, J.; Durrant, J. R.; Bradley, D. D. C.; Giles, M.; McCulloch, I.; Ha, C. S.; Ree, M. A strong regioregularity effect in self-organizing conjugated polymer films and highefficiency polythiophene: fullerene solar cells. Nat. Mater. 2006, 5(3), 197-203.

3 Erb, T.; Zhokhavets, U.; Gobsch, G.; Raleva, S.; Stühn, B.; Schilinsky, P.; Waldauf, C.; Brabec, C. J. Correlation between structural and optical properties of composite polymer/fullerene films for organic solar cells. Adv. Funct. Mater. 2005, 15(7), 1193-1196.

4 Chen T.-A.; Wu X.; Rieke R. D. Regiocontrolled synthesis of poly(3alkylthiophenes) mediated by rieke zinc: Their characterization and solid-state properties. J. Am. Chem. Soc. 1995, 117(1), 233-244.

5 Yang, X.; van Duren, J. K. J.; Rispens, M. T.; Hummelen, J. C.; Janssen, R. A. J.; Michels, M. A. J.; Loos, J. Crystalline organization of a methanofullerene as used for plastic solar-cell applications. $\quad$ Adv. Mater. 2004, 16(9-16), 802-806.

6 Wu, F. C.; Huang, Y. C.; Cheng, H. L.; Chou, W. Y.; Tang, F. C. Importance of disordered polymer segments to microstructure-dependent photovoltaic properties of polymer-fullerene bulk heterojunction solar cells. J. Phys. Chem. C 2011, 115(30), 15057-15066.

7 Kaçuş H.; Aydoğan Ş.; Biber M.; Metin Ö.; Sevim M. The power conversion efficiency optimization of the solar cells by doping of (Au:Ag) nanoparticles into P3HT:PCBM active layer prepared with chlorobenzene and chloroform solvents. Mater. Res. Express. 2019, 6(9), 095104.

8 Yang X.; Loos J.; Veenstra S. C.; Verhees W. J. H.; Wienk M. M.; Kroon J. M.; Michels M. A. J.; Janssen R. A. J. Nanoscale morphology of high-performance 
polymer solar cells. Nano Lett. 2005, 5(4), 579-583.

9 Campoy-Quiles, M.; Ferenczi, T.; Agostinelli, T.; Etchegoin, P. G.; Kim, Y.; Anthopoulos, T. D.; Stavrinou, P. N.; Bradley, D. D. C.; Nelson, J. Morphology evolution via self-organization and lateral and vertical diffusion in polymer: fullerene solar cell blends. Nat. Mater. 2008, 7(2), 158-164.

10 Gao, J.; Thomas, A. K.; Johnson, R.; Guo, H.; Grey, J. K. Spatially resolving ordered and disordered conformers and photocurrent generation in intercalated conjugated polymer/fullerene blend solar cells. Chem. Mater. 2004, 26(15), 43954404.

11 Clark, J.; Silva, C.; Friend, R. H.; Spano, F. C. Role of intermolecular coupling in the photophysics of disordered organic semiconductors: aggregate emission in regioregular polythiophene. Phys. Rev. Lett. 2007, 98(20), 206406.

12 Zhou, L.; Zhou, J.; Lai, W.; Yang, X. D.; Meng, J.; Su, L. B.; Gu, C. J.; Jiang, T.; Pun, E. Y. B.; Shao, L. Y.; Petti, L.; Sun, X. W.; Jia, Z. H.; Li, Q. X.; Han, J. G.; Mormile, P. Irreversible accumulated SERS behavior of the molecule-linked silver and silver-doped titanium dioxide hybrid system. Nat. Commun. 2020, 11(1), 10. 